\title{
MICRO-SCALE ELECTROCHEMICAL GAS SENSOR FOR SELECTIVE DETECTION OF VOLATILE POLLUTANTS
}

\author{
Pierre-Alexandre Gross ${ }^{* a, c}$, Tom Larsen ${ }^{a, b}$, Frédéric Loizeau ${ }^{a}$ \\ Thomas Jaramillo ${ }^{a}$, Denis Spitzer ${ }^{c}$ and Beth L. Pruitt ${ }^{a}$

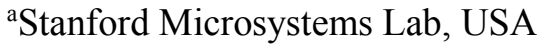 \\ ${ }^{b}$ Ecole Polytechnique Fédérale de Lausanne, Switzerland \\ ${ }^{\mathrm{c} N S 3 E}$, UMR 3208 ISL/CNRS/UNISTRA, France
}

\begin{abstract}
A micro fabricated chemical gas sensor based on the working principle of an electrochemical cell is presented along with tests in the detection of $\mathrm{CO}$ as a model pollutant. The sensor is composed of two Pt electrodes and a Nafion membrane acting as proton transporting medium. The fabrication process is presented as well as the test setups used for characterizing the sensor. The early results show that the sensor is capable of performing cyclic voltammetry when subjected to a gas flow and show the presence an oxidation peak of $\mathrm{CO}$ into $\mathrm{CO}_{2}$ at a precise applied potential.
\end{abstract}

\section{INTRODUCTION}

The most promising and developed technology for micro fabricated chemical gas sensor is based on the measurement of a resistance change between two electrodes as an chemical specie adsorbs on the medium in between them. That sensing layer is usually a semiconducting metal oxide such as $\mathrm{ZnO}$ [1], $\mathrm{CuO}$ [2], $\mathrm{TiO}_{2}$ [3] and $\mathrm{SnO}_{2}$ [4]. The sensing layer is heated to a high temperature (about $300{ }^{\circ} \mathrm{C}$ ) by a heater situated under it which induces an increase in the concentration of reactive oxygen ions at the surface of the sensing layer [5]. Those anions react with the adsorbed pollutant inducing an electron variation in the semiconductor and thus a resistance variation.

Besides being completely compatible with conventional micro fabrication processes, this type of sensor can also benefit from all of
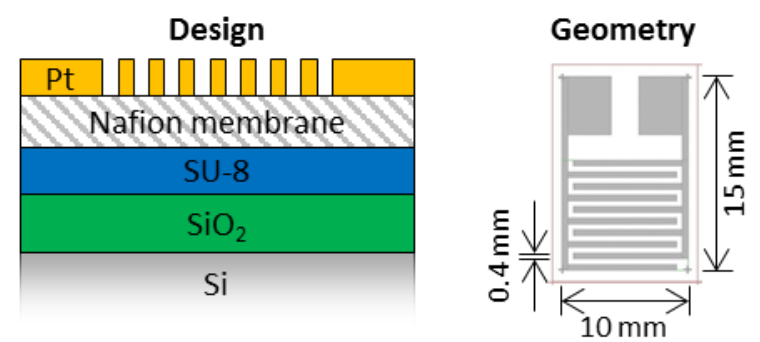

\begin{tabular}{|l|c|}
\hline \multicolumn{2}{|c|}{ Characterization results } \\
\hline \multicolumn{1}{|c|}{ Process step } & Measurements \\
\hline Oxidation & $920 \mathrm{~nm}$ \\
\hline Adhesion layer & $9.6 \mu \mathrm{m}$ \\
\hline Nafion deposition & $300-600 \mathrm{~nm}$ \\
\hline Metallization & $110-120 \mathrm{~nm}$ \\
\hline
\end{tabular}

Figure 1 : Topology, layout and characterization results of the micro electrochemical gas sensor. the various nanofabrication techniques developed for metal oxides to increase substantially their sensitivity [6].

However, in order to achieve any degree of selectivity, it is necessary to combine several of this type of sensors, in an array, with different sensing layers [7].

In order to achieve selectivity on a single sensor and at room temperature, one could use the redox potential which is a characteristic of any chemical specie. To do that, the species can be oxidized or reduced in an electrochemical cell configuration. Upon reaction, an increase in current is generated, which is measured as the redox potential of the specie is applied.

However, it is necessary to have a third electrode, called reference electrode, to be able to identify the species getting oxidized and reduced. This electrode is composed of a redox couple whose redox potential is well known and does not vary in the experimental conditions. It is by measuring the voltage between that reference electrode and the working electrode that it is possible to identify the species engaged in the electrochemical reactions thanks to the Nernst equation.

The development of a gas sensor based on this working principle would require fabrication of a fully solid state electrochemical cell. Among other possibilities, such as ionic conducting hydrogels [8] or zirconia based materials [9], the liquid electrolyte can be replaced by an ionic conductive polymer such as Nafion ${ }^{\circledR}$.

Nafion is proton conducting membrane largely used in fuel cells [10]. In particular in Proton Exchange Membrane Fuel Cells
Experiment in liquid 3 electrodes

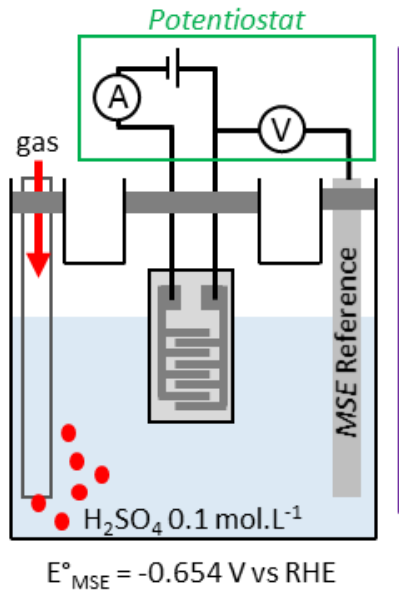

Experiment in gas phase 2 electrodes

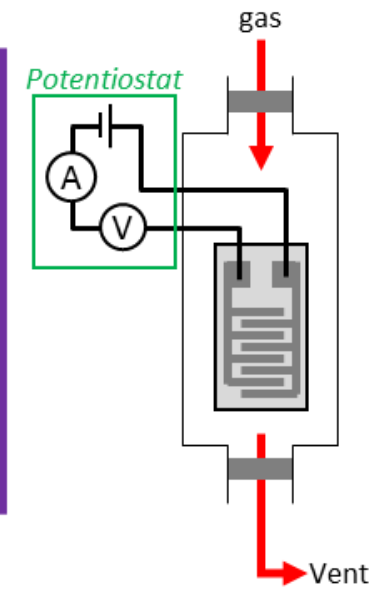

Figure 2: Electrochemical characterization setup (A) and sensor test setup (B). 

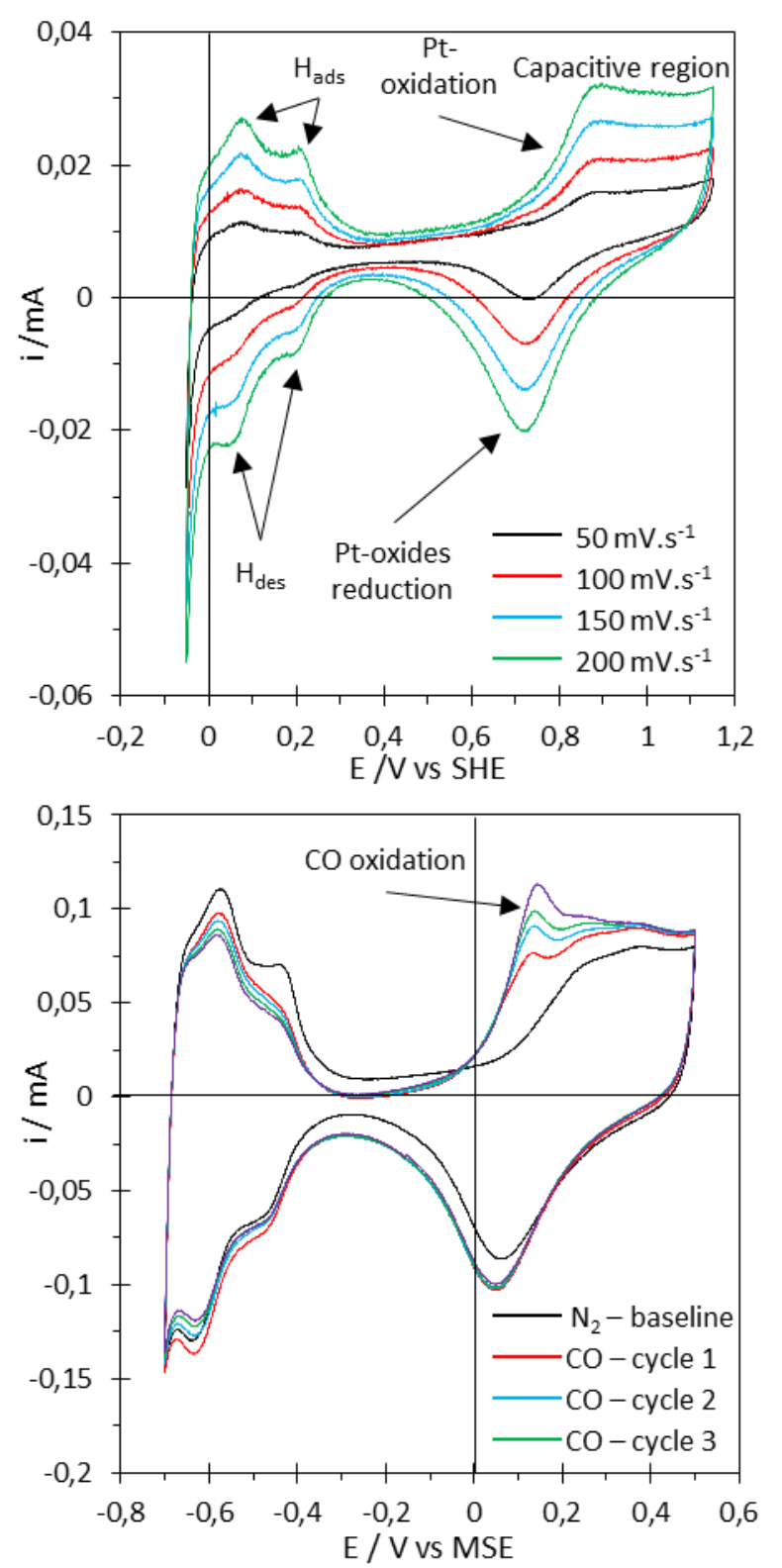

Figure 3 : Electrochemical characterization under $N_{2}(A)$ and under $C O(B)$.

(PEMFC) which are reducing $\mathrm{O}_{2}$ and oxidizing $\mathrm{H}_{2}$ in acidic conditions and at room temperature. In this example, the Nafion membrane is playing the role of the electrolyte, transporting the protons from one side to the other of the cell. It is a polymer composed of a teflon-like backbone and a sulfonic head. When hydrated, it forms clusters around water [11], and when acidified, the sulfonic groups allow proton transport [12].

Besides of being used in conventional fuel cell as described earlier, Nafion is also a promising material to be used in micro-fuel cells were it is used to separate the cathode and the anode while transporting protons [13]. The design developed in those devices have largely inspired the present work [14].

\section{The sensor}

The sensor proposed in this paper is an attempt to prove the feasibility of the electrochemical analysis of organic species dissolved in the gas phase. To obtain a fully solid state sensor, Nafion will be used as ionic conductive electrolyte, and the electrodes will be made of $\mathrm{Pt}$. Pt is chosen because its electrochemical and electrocatalytic properties, and its poisoning by $\mathrm{CO}$ in fuel cells is well documented [15], [16].

\section{EXPERIMENTAL SECTION}

\section{Fabrication process}

First, $100 \mathrm{~mm}$ diameter, $525 \mu \mathrm{m}$ thick L-test Si wafers were processed with standard cleaning procedure in the following order: i) $90 \% \quad \mathrm{H}_{2} \mathrm{SO}_{4} / \mathrm{H}_{2} \mathrm{O}_{2}$ (piranha), ii) $50: 1 \mathrm{HF}$ (clean) iii) $5: 1: 1$ $\mathrm{H}_{2} \mathrm{O}: \mathrm{H}_{2} \mathrm{O}_{2}: \mathrm{NH}_{4} \mathrm{OH}$ iv) 5:1:1 $\mathrm{H}_{2} \mathrm{O}: \mathrm{H}_{2} \mathrm{O}_{2}: \mathrm{HCl}$ (diffusion clean). A $1 \mu \mathrm{m}$ thick Si oxide layer is then grown on the substrate by wet oxidizing annealing at $1100{ }^{\circ} \mathrm{C}$ for $2 \mathrm{~h} 15 \mathrm{~min}$.

Our studies have showed that the Nafion adheres poorly to the $\mathrm{SiO}_{2}$ substrate, which is why a $10 \mu \mathrm{m}$ thick SU-8 2010 layer was first spin coated on the substrate at $1500 \mathrm{rpm}$ for $5 \mathrm{sec}$ and $3000 \mathrm{rpm}$ for $15 \mathrm{sec}$. The layer is then exposed to a $17 \mathrm{~mW} \cdot \mathrm{cm}^{-2}, 365 \mathrm{~nm}$ $O A I{ }^{\circledR} \mathrm{UV}$ exposer for $7 \mathrm{sec}$, and backed at $85^{\circ} \mathrm{C}$ for $2 \mathrm{~min}$ to ensure hardening and drying of the SU-8. Prior to deposition of the Nafion layer, the SU-8 coated substrate is subjected to $30 \mathrm{sec}$ of $\mathrm{O}_{2}$ plasma etching.

The Nafion layer is deposited by spin coating a D1021 Nafion ${ }^{\circledR}$ aqueous dispersion in three consecutive identical steps, which have been optimized to obtain a thickness of $300 \mathrm{~nm}$, of $5 \mathrm{sec}$ at $500 \mathrm{rpm}$ followed by $30 \mathrm{sec}$ at $1500 \mathrm{rpm}$. Each spin coating step is followed by a $2 \mathrm{~min}$ back at $65^{\circ} \mathrm{C}$. The deposition process is finished by a $1 \mathrm{~h}$ backing at $110^{\circ} \mathrm{C}$ to ensure evaporation of all solvent for upcoming photolithography steps.

The patterns of the electrodes are transmitted on the wafer by a typical liftoff process. The HMDS treatment generally performed prior to the coating of the resist is skipped to avoid any chemical modification of the Nafion layer. A $3 \mu \mathrm{m}$ thick SPR220-3 photoresist is spin coated and backed at $90{ }^{\circ} \mathrm{C}$ for $2 \mathrm{~min}$. The wafer is then exposed to a $15 \mathrm{~mW} \cdot \mathrm{cm}^{-2}, 365 \mathrm{~nm}$ UV light, through a transparency mask displaying the geometry of the sensor showed on Figure 1 in a hard contact mode for $3 \mathrm{sec}$.

The geometry of the sensor is simple and composed of two interdigitated electrodes with two larger pads to allow electrical contact as shown on Figure 1. After exposure, the photoresist is by spin coating of the corresponding chemical developer, rinsing and drying.

As final step, a $100 \mathrm{~nm}$ thick Pt layer is deposited by e-beam evaporation at a $1 \AA . \mathrm{s}^{-1}$ rate, and the resist is stripped in an acetone bath for $2 \mathrm{~h}$. The sensors are then rinsed, dried and diced. Prior to characterization or testing, the Nafion layer needs to be rehydrated and acidified in order to have optimum proton conductivity. The sensor is immersed in a series of baths at $80{ }^{\circ} \mathrm{C}$ for $15 \mathrm{~min}$ in each: i) $\mathrm{H}_{2} \mathrm{O}_{2} 2 \%$ vol. in $\mathrm{H}_{2} \mathrm{O}$, ii) $\mathrm{H}_{2} \mathrm{SO}_{4} 0.1$ mol.L $\mathrm{L}^{-1}$ iii) $\mathrm{H}_{2} \mathrm{O}$. After that treatment the sensors are ready to be characterized and tested. The final design of the sensor is presented on Figure 1.

\section{Characterization and test methods}

The topological characterization of the sensor was made with a profilometer and the results are presented in the table of Figure 1. All the measured parameters are in the acceptable range compared to the target thicknesses. Concerning the Nafion layer, the measurement of its thickness revealed a quite important irregularity spanning from 300 to $600 \mathrm{~nm}$ across the wafer.

The sensors are also characterized by electrochemistry in a conventional electrochemical cell in a three electrodes configuration. The test setup is presented on Figure $2 \mathrm{~A}$ and 

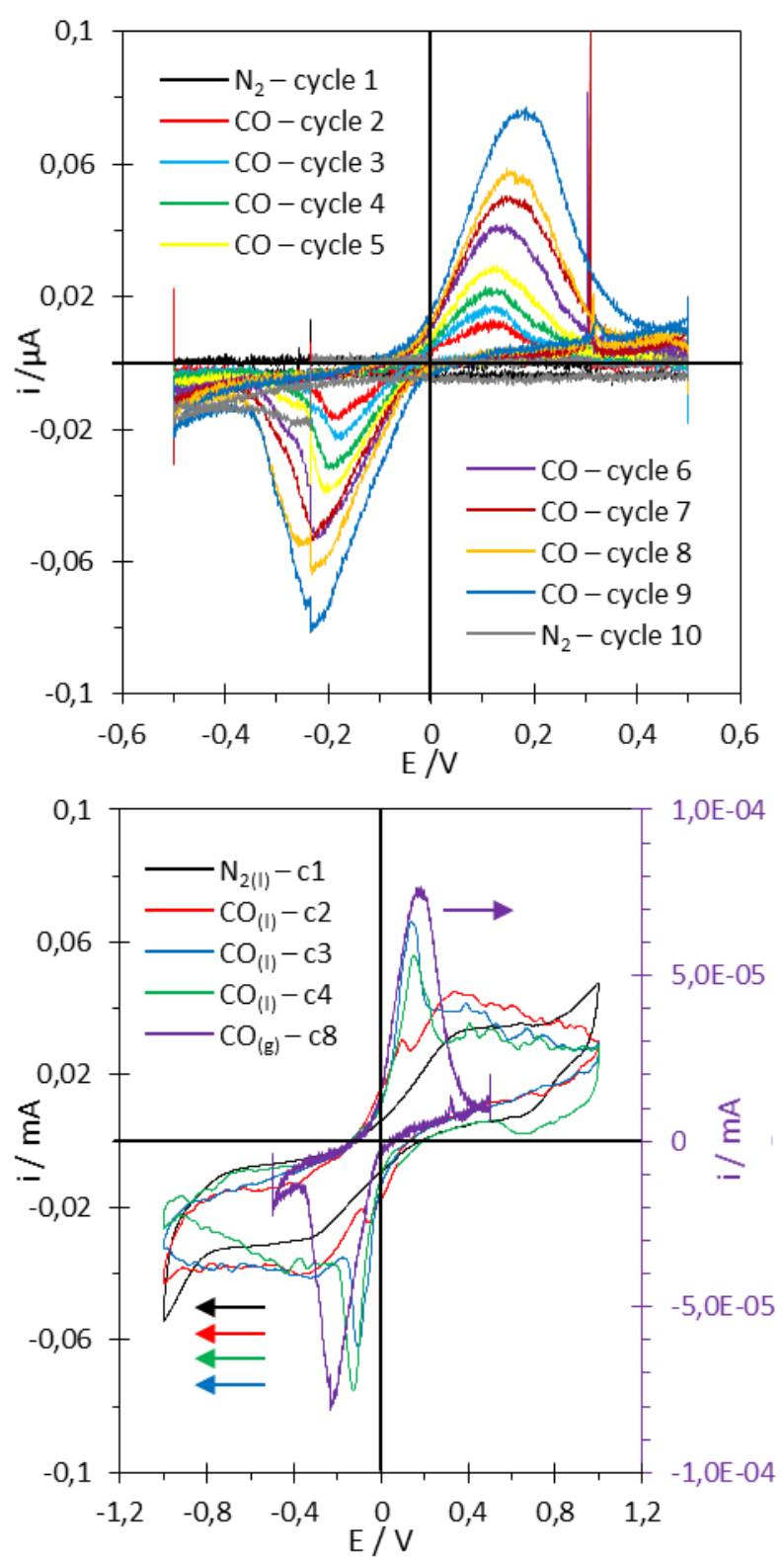

Figure 4: Curves of the cyclic voltammetry performed in the gas phase (A) and in the electrochemical cell in a two electrodes configuration (B).

represents the sensor with its two electrodes being respectively the working and counter electrodes, connected to an external Mercury/Mercury Sulfate Electrode (MSE) reference electrode $\left(\mathrm{E}^{\circ}\right.$ MSE $=-0.654 \mathrm{~V}$ vs SHE) through and Biologic ${ }^{\circledR}$ SP-300 potentiostat. All three electrodes are immersed in a $0.1 \mathrm{~mol} . \mathrm{L}^{-1}$ $\mathrm{H}_{2} \mathrm{SO}_{4}$ solution and cyclic voltammetry is performed between various potentials and at different sweep rates. In cyclic voltammetry, the potential (in V) is applied and swept between the working and the counter electrodes. The corresponding current (in $\mathrm{mA}$ ) flowing between the working and counter electrodes is recorded and plotted against the voltage measured between the working and the reference electrode.

The testing of the sensors for the detection of volatile pollutants are performed in a custom made test chamber. The electrodes are connected to the same potentiostat in a two electrodes configuration.
The test chamber is under constant gas flow from either $\mathrm{N}_{2}$ or pure $\mathrm{CO}$ with a flow rate of $20 \mathrm{~cm}^{3} \cdot \mathrm{min}^{-1}$. While the test chamber is under gas flow, the voltage is swept between the two electrodes of the sensor from -1.0 to $1.0 \mathrm{~V}$ with a $200 \mathrm{mV} . \mathrm{s}^{-1}$ sweep rate. The complete test setup is presented on Figure 2B.

\section{RESULTS AND DISCUSSION}

\section{Design of the sensor}

The sensor has been designed with a few considerations in mind. First, the fabrication steps should impact the least possible the Nafion layer to keep its chemical integrity. In terms of redox chemical reaction, the key features are the "triple points", which are the interfaces were Pt, Nafion and the gas phase meet. With this in mind, the Pt electrodes do not need to be very thick, and it is anticipated that their thickness will not impact the sensitivity significantly. However, the main constraint for the geometry is the separation between the electrodes fingers because the ionic conductivity of Nafion drops drastically above $500 \mu \mathrm{m}$.

Keeping the design simple is also necessary to prove that the proposed sensing mechanism might be compatible with mass production.

\section{Electrochemical characterization}

The electrochemical characterization of the sensor consists of a set of two experiments performed in the configuration of Figure $2 \mathrm{~A}$. The first one is done with $\mathrm{N}_{2}$ bubbling in the cell, and the second one is with $\mathrm{CO}$ bubbling.

The experiment with $\mathrm{N}_{2}$ is necessary to check if the Pt electrode are well positioned at the surface of the Nafion layer and that the Nafion layer is indeed able to conduct protons as expected after the fabrication process. The results are shown on Figure 3A were one can see a typical CV curve for polycrystalline $\mathrm{Pt}$ in acidic medium [17]. The quality of the Pt surface as well as the ionic conductivity of the Nafion are confirmed by the presence of all expected electrochemical signals. The observed signals are $\mathrm{H}$ adsorption/desorption located between 0 and $0.25 \mathrm{~V}$ vs SHE, the Pt oxide formation starting at $0.7 \mathrm{~V}$ vs SHE, the capacitive region plateau and the Pt oxides reduction peak at $0.7 \mathrm{~V}$ vs SHE. The experiment is conducted at several sweep rates from $50 \mathrm{mV} \cdot \mathrm{s}^{-1}$ to $200 \mathrm{mV} . \mathrm{s}^{-1}$. All electrochemical signals are increasing in current with the increasing sweep rate, which is expected for cyclic voltammetry.

The second electrochemical characterization is conducted in similar conditions but with $\mathrm{CO}$ bubbling. The resulting curve is showed on Figure 3B. On can see that the general shape of the curve is similar to the one obtained under $\mathrm{N}_{2}$ and that an oxidation peak appears at $0.15 \mathrm{~V}$ vs MSE. This peak corresponds to the oxidation of $\mathrm{CO}$ into $\mathrm{CO}_{2}$ [16] according to its position on the potential scale when converted on the $\mathrm{SHE}$ scale $\left(\mathrm{E}_{(\mathrm{Pt})}\left(\mathrm{CO}_{2} / \mathrm{CO}\right) \approx 0.8 \mathrm{~V}\right.$ vs $\left.\mathrm{SHE}\right)$. The presence of this oxidation peak confirms that the sensor is indeed capable of detecting CO by measuring an increasing current at a specific applied potential corresponding to its redox potential. In addition of the presence of this oxidation peak, one can also see a slight decrease in current of the $\mathrm{H}$ ads/des peaks. This phenomena tends to confirm the nature of the oxidation of $\mathrm{CO}$ into $\mathrm{CO}_{2}$ as the adsorption of $\mathrm{CO}$ on Pt occurs on the same catalytic sites as $\mathrm{H}$ [18].

\section{CO detection tests}

As model pollutant $\mathrm{CO}$ was chosen, and its oxidation into $\mathrm{CO}_{2}$ for validation of the electrochemical capabilities of the sensor. The experiment is conducted on the setup showed on Figure 2B. As the 
voltage is cycled between -0.5 and $0.5 \mathrm{~V}$ with a $200 \mathrm{mV} . \mathrm{s}^{-1}$ sweep rate, the gas flow is alternatively switch from $\mathrm{N}_{2}$ to $\mathrm{CO}$ and to $\mathrm{N}_{2}$ again. In this configuration, the voltage is swept from one limit to the other in $5 \mathrm{~s}$, which means that the observed changes in signal are happening on that time scale. The first cycles under $\mathrm{N}_{2}$ allows to obtain a baseline to better identify the signal obtained under CO. The last cycles under $\mathrm{N}_{2}$ are to show the quick response of the sensor.

The resulting curve shown on Figure $4 \mathrm{~A}$ shows that under $\mathrm{N}_{2}$ (black line), no signal is detected at any applied voltage. When the CO flow is turned on, immediately an oxidation peak appears at 0.2 and $-0.2 \mathrm{~V}$ with increasing current over cycles. The charge of both peaks being very close $(0.3 \mu \mathrm{C})$, it seems that they are the signal of the same redox process happening alternatively on both electrodes as the polarization changes. As the gas flow is switch from $\mathrm{CO}$ to $\mathrm{N}_{2}$ again, the oxidation signal disappears immediately, showing that the sensors response is relatively quick (ca. $5 \mathrm{~s}$ ).

In the absence of reference electrode, it is impossible to identify the nature of that redox reaction. However, in order to confirm that it is indeed $\mathrm{CO}$ oxidation into $\mathrm{CO}_{2}$, a similar experiment is performed in liquid environment.

The sensor is placed back in the electrochemical cell with the same electrolyte, but this time, the reference electrode is not connected. Again, $\mathrm{N}_{2}$ and $\mathrm{CO}$ are bubbled alternatively in the cell, and the resulting curve is shown on Figure 4B. In this two electrodes configuration, the shape of the curve observed previously is lost and becomes symmetrical with respect to 0 as is the curve obtained in the gas phase. The only shape which is observed under $\mathrm{N}_{2}$ is the capacitive region of Pt. However, as $\mathrm{CO}$ is bubble in the cell, an oxidation peak appears at 0.2 and $-0.2 \mathrm{~V}$, just before the capacitive region, exactly as it was observed on Figure $3 \mathrm{~B}$. This peak can be attributed to $\mathrm{CO}$ oxidation, and its position in this configuration matches well with the position of the peak observed in the gas phase experiment. Obtaining this curve confirms that the result from Figure $4 \mathrm{~A}$ is indeed $\mathrm{CO}$ getting oxidized in $\mathrm{CO}_{2}$ and thus that the sensor is capable of performing electrochemical measurements in gaseous conditions, and can identify the specie being adsorbed unlike conventional metal oxide based sensors measuring a change in resistance indicating that a specie is present, but cannot be identified [19].

\section{CONCLUSION}

In summary, the design and fabrication process of a micro electrochemical gas sensor were presented along with both topological and electrochemical characterizations. It has been showed that the sensor behaves just as a typical working/counter electrodes couple when connected to an external reference electrode in a conventional electrochemical cell.

Testing of the sensor for the detection of $\mathrm{CO}$ as model pollutant has proved that the sensor is capable of electrochemical measurements in the gas phase.

To further improve the current sensor, the research effort is now focused on the implementation of a reference electrode in order to achieve identification of species directly in working conditions.

\section{REFERENCES}

[1] Q. Wan, Q. H. Li, Y. J. Chen, T. H. Wang, X. L. He, J. P. Li, and C. L. Lin, "Fabrication and ethanol sensing characteristics of $\mathrm{ZnO}$ nanowire gas sensors," Appl. Phys. Lett., vol. 84, no. 18, pp. 36543656, May 2004.
[2] S.-W. Choi, A. Katoch, J.-H. Kim, and S. S. Kim, "Remarkable Improvement of Gas-Sensing Abilities in p-type Oxide Nanowires by Local Modification of the Hole-Accumulation Layer," ACS Appl. Mater. Interfaces, vol. 7, no. 1, pp. 647-652, Jan. 2015.

[3] T. Kida, M.-H. Seo, K. Suematsu, M. Yuasa, Y. Kanmura, and K. Shimanoe, "A Micro Gas Sensor Using TiO2 Nanotubes to Detect Volatile Organic Compounds," Appl. Phys. Express, vol. 6, no. 4, p. 047201, Apr. 2013.

[4] U. Hoefer, H. Böttner, A. Felske, G. Kühner, K. Steiner, and G. Sulz, "Thin-film $\mathrm{SnO} 2$ sensor arrays controlled by variation of contact potential - a suitable tool for chemometric gas mixture analysis in the TLV range," Sens. Actuators B Chem., vol. 44, no. 1-3, pp. 429-433, Oct. 1997.

[5] X. Liu, S. Cheng, H. Liu, S. Hu, D. Zhang, and H. Ning, "A Survey on Gas Sensing Technology," Sensors, vol. 12, no. 7, pp. 9635-9665, Jul. 2012.

[6] H. Nguyen, C. T. Quy, N. D. Hoa, N. T. Lam, N. V. Duy, V. V. Quang, and $\mathrm{N}$. V. Hieu, "Controllable growth of $\mathrm{ZnO}$ nanowires grown on discrete islands of Au catalyst for realization of planar-type micro gas sensors," Sens. Actuators B Chem., vol. 193, pp. 888-894, Mar. 2014.

[7] K. T. Ng, F. Boussaid, and A. Bermak, "A CMOS Single-Chip Gas Recognition Circuit for Metal Oxide Gas Sensor Arrays," IEEE Trans. Circuits Syst. Regul. Pap., vol. 58, no. 7, pp. 1569-1580, Jul. 2011.

[8] D. Kumar and S. A. Hashmi, "Ionic liquid based sodium ion conducting gel polymer electrolytes," Solid State Ion., vol. 181, no. 810, pp. 416-423, Mar. 2010.

[9] W. Sun, Z. Shi, M. Liu, L. Bi, and W. Liu, "An Easily Sintered, Chemically Stable, Barium Zirconate-Based Proton Conductor for High-Performance Proton-Conducting Solid Oxide Fuel Cells," Adv. Funct. Mater., vol. 24, no. 36, pp. 5695-5702, Sep. 2014.

[10] K. A. Mauritz and R. B. Moore, "State of Understanding of Nafion," Chem. Rev., vol. 104, no. 10, pp. 4535-4586, Oct. 2004.

[11] I. Pálinkó, B. Török, G. K. S. Prakash, and G. A. Olah, "Dehydrationrehydration characteristics of Nafion-H, Nafion-H supported on silica and Nafion-H silica nanocomposite catalysts studied by Infrared Microscopy," J. Mol. Struct., vol. 482-483, pp. 29-32, May 1999.

[12] Y. Nagao, "Highly Oriented Sulfonic Acid Groups in a Nafion Thin Film on Si Substrate," J. Phys. Chem. C, vol. 117, no. 7, pp. 32943297, Feb. 2013.

[13] A. D. Taylor, B. D. Lucas, L. J. Guo, and L. T. Thompson, "Nanoimprinted electrodes for micro-fuel cell applications," J. Power Sources, vol. 171, no. 1, pp. 218-223, Sep. 2007.

[14] K. Shah, W. C. Shin, and R. S. Besser, "Novel microfabrication approaches for directly patterning PEM fuel cell membranes," $J$. Power Sources, vol. 123, no. 2, pp. 172-181, Sep. 2003.

[15] Y. Wang, K. S. Chen, J. Mishler, S. C. Cho, and X. C. Adroher, "A review of polymer electrolyte membrane fuel cells: technology, applications, and needs on fundamental research," Appl. Energy, vol. 88, no. 4, pp. 981-1007, 2011.

[16] T. Vidaković, M. Christov, and K. Sundmacher, "The use of CO stripping for in situ fuel cell catalyst characterization," Electrochimica Acta, vol. 52, no. 18, pp. 5606-5613, May 2007.

[17] C. M. A. Brett and A. M. O. Brett, Electrochemistry principles, methods, and applications. Oxford; New York: Oxford University Press, 1993.

[18] N. M. Marković, B. N. Grgur, C. A. Lucas, and P. N. Ross, "Electrooxidation of $\mathrm{CO}$ and $\mathrm{H} 2 / \mathrm{CO}$ Mixtures on $\mathrm{Pt}(111)$ in Acid Solutions," J. Phys. Chem. B, vol. 103, no. 3, pp. 487-495, Jan. 1999.

[19] Y.-F. Sun, S.-B. Liu, F.-L. Meng, J.-Y. Liu, Z. Jin, L.-T. Kong, and J.H. Liu, "Metal Oxide Nanostructures and Their Gas Sensing Properties: A Review," Sensors, vol. 12, no. 3, pp. 2610-2631, Feb. 2012.

\section{ACKNWLEDGEMENTS}

Authors would like to acknowledge the funding contribution of the French Department of Defense (DGA) and $O A I \circledR$.

\section{CONTACT}

* Pierre-Alexandre Gross, pialgr@stanford.edu 